\title{
A HIGHER MEAL FREQUENCY MAY BE ASSOCIATED WITH DIMINISHED WEIGHT LOSS AFTER BARIATRIC SURGERY
}

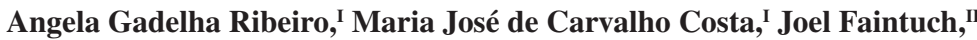 \\ Maria Carolina Gonçalves Dias ${ }^{\mathrm{III}}$
}

doi: $10.1590 / \mathbf{S 1 8 0 7 - 5 9 3 2 2 0 0 9 0 0 1 1 0 0 0 0 4}$

Ribeiro AG, Costa MJC, Faintuch J, Dias MCG. A higher meal frequency is associated with diminished weight loss after bariatric surgery. Clinics. 2009;64(11):1053-7.

OBJECTIVE: This study aimed to investigate the relationship between meal frequency, the occurrence of vomiting and weight loss among patients submitted to Roux-en-Y gastric bypass up to 9 months after surgery.

METHODS: Female patients $(\mathrm{n}=80)$ were followed at 3-month intervals for 9 months. Weight, BMI, 24-hour dietary recall, drug consumption and vomiting episodes were recorded and compared with nutritional outcome.

RESULTS: The BMI values at 3, 6 and 9 months were $45.1 \pm 9.7,39.9 \pm 7.6$ and $35.4 \pm 8.2 \mathrm{~kg} / \mathrm{m}^{2}$, respectively. The corresponding choleric intakes were $535.6 \pm 295.7,677.1 \pm 314.7$ and $828.6 \pm 398.2 \mathrm{kcal} /$ day, and the numbers of daily meals were $5.0 \pm$ 2.5, $4.7 \pm 1.8$ and $4.9 \pm 1.0$, respectively. The peak of vomiting episodes occurred within 6 months; however, patients tolerated this complication despite its high prevalence. A significant negative correlation between weight loss and diet fractioning, but not vomiting, was observed throughout the entire postoperative period $(\mathrm{P}=0.001)$.

CONCLUSIONS: 1) Frequent small meals were associated with a reduction in weight loss after gastric bypass and a decrease in vomiting episodes at 6 months, and 2) vomiting did not interfere with nutritional outcome. Unless required because of vomiting or other reasons, multiple small meals may not be advantageous after such intervention.

KEYWORDS: Roux-en-Y gastric bypass; Bariatric surgery; Morbid obesity; Calorie ingestion; Diet.

\section{INTRODUCTION}

The incidence of obesity in the U.S. has exponentially increased to epidemic proportions, increasing by more than $75 \%$ over the last 25 years. This fact allows obesity to currently be considered a major public health issue. The most recent NHANES data (1999-2004) estimate that among adults in the U.S., $66.3 \%$ are overweight or obese, $32.4 \%$ are obese and $4.8 \%$ are extremely obese. ${ }^{1}$

Diverse intervention strategies are being applied, and

\footnotetext{
I School of Nutrition, University of Paraíba (UFPB) - João Pessoa/PB, Brazil. "I Department of Gastroenterology, Faculdade de Medicina da Universidade de Sao Paulo - São Paulo/SP, Brazil.

IIINutrition Team (EMTN), Hospital das Clinicas da Faculdade de Medicina da Universidade de Sao Paulo - São Paulo/SP, Brazil.

Email: mjc.costa@terra.com.br

Tel: 55833216.7417 / 3235.3353

Received for publication on ???????

Accepted for publication on ?????????
}

Roux-en-Y gastric bypass (RYGB) ${ }^{2}$ is a prominent technique among them. It is an effective and relatively low-risk procedure to provide weight loss, which can generally be controlled on a short- or long-term basis. ${ }^{3}$

Although the number of surgeries and the number of published essays ${ }^{4-7}$ on this matter increase each year, the influences of postoperative food programs on weight loss have not been thoroughly investigated. This is especially true when it comes to meal frequency.

Some authors have suggested that a higher fractionation of meals would induce more weight loss. ${ }^{8-11}$ The mechanisms that explain such a relationship, however, are obscure and even paradoxical, ${ }^{12-14}$ raising doubts about the true advantage of multiple meals. Vomiting is not uncommon in this setting, and small amounts of food divided throughout the day may alleviate discomfort. ${ }^{2,4-7}$

The present study was designed to investigate the interactions between consumed meals, vomiting episodes 
and weight loss in bariatric patients up to 9 months after RYGB.

\section{METHODS}

\section{Population}

Morbidly obese female patients $(n=80)$ who had been submitted to RYGB were nutritionally followed over a 9-month period after surgery. Women were selected because they represent the majority of surgical candidates and because they allow us to obtain a homogeneous analysis of the results.

Surgical indication followed the accepted rules, namely, a body mass index $(\mathrm{BMI})>40 \mathrm{~kg} / \mathrm{m} 2$ independent of comorbidities or $>35 \mathrm{~kg} / \mathrm{m} 2$ in the presence of significant associated diseases. The prevalence of comorbidities was not targeted by the protocol, but results were not substantially different from those previously published (diabetes mellitus, 24\%; dyslipidemia, 52\%; arterial hypertension, 72\%; metabolic syndrome, $59 \%) .{ }^{15}$

Inclusion criteria were: age of 18-65 years, elective intervention and informed consent. Exclusion criteria were: sepsis, shock, coma, hospitalization or reoperation during the study period or refusal to participate in the study.

\section{Study design}

This study employed a prospective observational clinical protocol with outpatient subjects. Patients were interviewed at 3-month intervals between the $3^{\text {rd }}$ and $9^{\text {th }}$ postoperative months by a trained dietitian. General information was collected from hospital records and was confirmed during scheduled visits.

\section{Exclusions}

The study began with 160 subjects with a planned duration of 12 months. At the end of the study, only 80 were included, and only the first 9 months were analyzed because returns sharply diminished after this time.

\section{Surgical technique}

The open RYGBP involved the creation of a vertical gastric pouch of approximately $30 \mathrm{ml}$, a Roux-en-Y jejunal limb of $100 \mathrm{~cm}$ and a biliopancreatic limb of $60-80 \mathrm{~cm}$. The gastric reservoir had a length of $8-10 \mathrm{~cm}$ and a volume of $30-50 \mathrm{ml}$, and a silastic ring $(6.3 \mathrm{~cm}$ in circumference) was inserted around the pouch $3 \mathrm{~cm}$ proximal to the end-to-side gastrojejunal anastomosis to prevent future dilatation.

\section{Anthropometric variables}

Body weight, height, BMI and weight loss were recorded at each visit. Weight loss (absolute or as a percentage) was based on the following equation: Weight loss = Usual weight - Present weight.

\section{Dietetic methods}

Diet fractionation considered all options adopted by the patients, from just one or two meals/day up to more than six meals/day. Vomiting episodes were numerically registered, irrespective of the severity of the event. Dietary recall $(24 \mathrm{~h})$ was analyzed using the Virtual Nutri software package (São Paulo, SP, Brazil), which has been programmed for Brazilian foods and meal sizes.

Recall was performed at three different occasions at the end of each quarter, including one weekend, and the median score was used to evaluate macronutrients.

Interviews were conducted by an experienced dietitian. Patients who stated that they were ill or, for some other reason, had changed their diet within the last 48 hours were scheduled for another date. All consumed foods and drinks were recorded, and details regarding the ingredients and preparation technique, or food brand in the case of industrialized items, were collected. Standard cups, dishware and food portions were described, and more information was requested from the patient in case of doubt before registering the questionnaire.

Final verification emphasized forgotten items, such as occasional cookies, sugar- or alcohol-containing drinks, as well as midnight snacks.

\section{Ethical considerations}

Informed consent was obtained from all subjects, and the protocol was approved by the ethical committees of the two involved institutions.

\section{Statistical analysis}

Values are presented as means \pm SD. An analysis of variance (ANOVA) was used to compare numerical variables (anthropometry and calories) after confirmation of normality by the Kolmogorov-Smirnov test. A comparison of diet fractionation means (organized into six categories) was performed using the Tukey test. Qualitative data (vomiting) was examined by chi-squared analysis or a Fisher's exact test. Pearson's correlation analysis was used to evaluate the variables of weight loss, diet fractionation, vomiting episodes and calories. A significance level of $5 \%(\mathrm{P}<0.05)$ was adopted in all circumstances. 
Table 1 - General population profile

\begin{tabular}{|c|c|c|c|c|}
\hline Variables & Preoperative & 3 months & 6 months & 9 months \\
\hline Weight (kg) & $129.1 \pm 27.1$ & $113.4 \pm 25.4$ & $99.9 \pm 19.8$ & $88.0 \pm 21.6$ \\
\hline BMI $\left(\mathrm{kg} / \mathrm{m}^{2}\right)$ & $53.5 \pm 10.1$ & $45.1 \pm 9.7$ & $39.9 \pm 7.6$ & $35.4 \pm 8.2$ \\
\hline Weight loss (kg) & & $15.7 \pm 7.3 *$ & $11.3 \pm 4.9$ & $11.5 \pm 12.7$ \\
\hline Weight loss (\%) & & $12.2 \pm 4.5$ & $10.3 \pm 4.7$ & $13.5 \pm 8.8$ \\
\hline Calories (Kcal/day) & & $535.6 \pm 295.7$ & $677.1 \pm 314.7$ & $828.6 \pm 398.2$ \\
\hline Vomiting (\%) & & $31.3(25 / 80)$ & $50.0(40 / 80)^{* *}$ & $43.8(35 / 80)$ \\
\hline Number of meals & & $5.0 \pm 2.5$ & $4.7 \pm 1.8$ & $4.9 \pm 1.0$ \\
\hline
\end{tabular}

(*) $\mathrm{P}=0.044$ (ANOVA); $(* *) \mathrm{P}=0.47$ (chi-square analysis)

\section{RESULTS}

The general findings of the population are organized in Table 1. Maximum weight loss, at least in absolute values, occurred in the first quarter. The rate of absolute weight loss decreased at the later time points. Dietary intake gradually increased, although always remaining well below the recommended allowances. Vomiting episodes increased and peaked at 6 months, but were at common levels by 9 months.

The number of meals did not influence the BMI, weight loss or food intake up to 6 months. Nevertheless, when the entire study period was considered, diet fractionation had an impact on weight loss (Table 2).

In the first 6 months, no differences in BMI or dietary choleric intake could be attributed to diet fractionation. Analysis of the entire 9 months, however, revealed that a three-meals/day regimen was associated with the highest
Table 2 - Nutritional impact of daily meal frequency (ANOVA "F" test)

\begin{tabular}{lccc}
\hline Period & BMI & Weight loss & Calories \\
\hline 3 months & $\mathrm{F}=1.28 \mathrm{NS}$ & $\mathrm{F}=0.28 \mathrm{NS}$ & $\mathbf{F}=\mathbf{2 . 8 9} \mathbf{P}<\mathbf{0 . 0 5}$ \\
6 months & $\mathrm{F}=0.13 \mathrm{NS}$ & $\mathrm{F}=0.35 \mathrm{NS}$ & $0.88 \mathrm{NS}$ \\
9 months & $\mathrm{F}=0.51 \mathrm{NS}$ & $\mathbf{F}=\mathbf{1 2 , 5 7} \mathbf{P}<\mathbf{0 . 0 1}$ & $0.93 \mathrm{NS}$ \\
\hline
\end{tabular}

NS = Not significant

weight loss, as compared to that obtained with a larger number of meals (Table 3 ).

A Pearson correlation confirmed that diet fractionation, vomiting episodes and choleric intake did not interfere with the outcome at 3 months. By 9 months, however, there was a significant negative correlation with a $1 \%$ probability $(\mathrm{P}<$ 0.01 ) between weight loss and diet fractionation, indicating that a greater number of meals/day was associated with less

Table 3 - Nutritional course and diet fractionation

\begin{tabular}{|c|c|c|c|c|}
\hline Postop period & Fractionation & $\operatorname{BMI}\left(\mathrm{kg} / \mathrm{m}^{2}\right) *$ & Weight loss (kg) & Calories (Kcal/day) \\
\hline \multirow[t]{5}{*}{3 months } & 3 times $(\mathrm{n}=8)$ & $42.6 \pm 8.3$ & $18.2 \pm 11.2$ & $290.5 \pm 181.5 * * *$ \\
\hline & 4 times $(n=26)$ & $44.8 \pm 10.5$ & $14.9 \pm 6.6$ & $523.5 \pm 272.2$ \\
\hline & 5 times $(\mathrm{n}=27)$ & $45.1 \pm 8.9$ & $16.9 \pm 8.7$ & $572.8 \pm 265.3$ \\
\hline & 6 times $(\mathrm{n}=9)$ & $52.4 \pm 13.2$ & $14.6 \pm 2.7$ & $814.2 \pm 466.5 * * * *$ \\
\hline & More than 6 times $(n=8)$ & $41.2 \pm 8.5$ & $15.4 \pm 3.3$ & $494.2 \pm 241.3$ \\
\hline \multirow[t]{5}{*}{6 months } & Once or twice $(n=5)$ & $39.5 \pm 12.8$ & $9.5 \pm 1.1$ & $312.9 \pm 182.5$ \\
\hline & 3 times $(n=6)$ & $39.5 \pm 7.4$ & $14.0 \pm 1.5$ & $683.1 \pm 128.2$ \\
\hline & 4 times $(n=25)$ & $39.7 \pm 10.2$ & $10.9 \pm 5.8$ & $661.8 \pm 257.5$ \\
\hline & 5 times $(n=24)$ & $41.1 \pm 6.3$ & $10.9 \pm 4.9$ & $753.1 \pm 362.7$ \\
\hline & 6 times $(n=16)$ & $38.9 \pm 5.5$ & $11.8 \pm 4.9$ & $665.20 \pm 352.9$ \\
\hline \multirow[t]{4}{*}{9 months } & 3 times $(\mathrm{n}=5)$ & $30.4 \pm 11.4$ & $36.4 \pm 16.3$ & $534.5 \pm 414.8$ \\
\hline & 4 times $(n=17)$ & $33.0 \pm 6.3$ & $14.5 \pm 12.0 * *$ & $852.0 \pm 536.2$ \\
\hline & 5 times $(n=28)$ & $35.9 \pm 8.2$ & $9.9 \pm 5.1 * *$ & $862.7 \pm 371.1$ \\
\hline & 6 times $(n=18)$ & $35.4 \pm 10.2$ & $12.4 \pm 4.5 * *$ & $741.0 \pm 257.7$ \\
\hline
\end{tabular}

Categories with less than five patients were eliminated; $(*)$ No significant difference at any time; $(* *)$ Three-fold reduction in comparison during the same period $(\mathrm{P}<0.05)$; (***) Reduced for the period, $\mathrm{P}<0.05 ;(* * * *)$ Increased for the period, $\mathrm{P}<0.05$ 
Table 4 - Correlation between weight loss, diet fractionation and vomiting episodes

\begin{tabular}{lll}
\hline Postoperative period & Variables & P \\
\hline 3 months & Weight loss x DF & 0.609 \\
& Weight loss x Vomiting & 0.593 \\
& Weight loss x Cal & 0.063 \\
& DF x Vomiting & 0.127 \\
& DF x Calories & 0.677 \\
6 months & Vomiting x calories & 0.689 \\
& Weight loss x DF & 0.854 \\
& Weight loss x Vomiting & 0.760 \\
& Weight loss x Cal & 0.264 \\
DF x Vomiting & $\mathbf{0 . 0 3 8}(\mathbf{r}=\mathbf{- 0 . 2 6 1 )}$ \\
& DF x Calories & 0.332 \\
& Vomiting x Calories & 0.937 \\
& Weight loss x DF & $\mathbf{0 . 0 0 1}(\mathbf{r}=\mathbf{- 0 . 4 0 4 )}$ \\
& Weight loss x Vomiting & 0.308 \\
& Weight loss x Cal & 0.051 \\
& DF x Vomiting & 0.264 \\
& DF x Calories & 0.271 \\
Vomiting x Calories & 0.516 \\
\hline
\end{tabular}

DF: Diet fractionation; Vomiting: Number of vomiting episodes; Cal: Calorie intake; P-values: Significant results are shown in bold.

weight loss. Conversely, vomiting improved with more meals by 6 months (Table 4 ).

Although weight loss was influenced by the frequency of meals, the effect was not significant. This tended to be analogously associated with energy intake, especially at 3 months $(\mathrm{P}=0.063, \mathrm{NS})$ and at 9 months $(\mathrm{P}=0.051, \mathrm{NS})$.

\section{DISCUSSION}

Gastric bypass is not the only bariatric technique available. There are a variety of modalities for weight loss available around the world. It is, however, still respected as the gold standard and the benchmark to which other approaches have been compared. ${ }^{2,4,6,15}$

The pre-bariatric weight in this series was $129.1 \pm 27.1$ $\mathrm{kg}$, a value almost identical to that observed in the study of Ocon et al. ${ }^{16}(129.7 \pm 25.6 \mathrm{~kg})$. Weight curves during the postoperative period are more variable, as they suffer from the impact of previous weight, dietary pattern, comorbidities and complications. According to Crookes et al. and others, ${ }^{16-}$ ${ }^{19}$ patients are expected to lose $25-32 \%$ of body weight during the first 6-12 months, which is roughly the range observed in this study.

Vomiting is a recognized side effect due to the narrowed gastric outlet, especially if patients eat rapidly or swallow large chunks of food without chewing, and may affect $8-49 \%$ of subjects. ${ }^{6.19-21}$ When persistent, it may precipitate protein-calorie malnutrition as well as Wernicke`s encephalopathy. ${ }^{22,23}$ In the current series, somewhat higher than average values were found, with an increasing tendency up to 6 months. These values, however, decreased around 9 months. Multiple meals were beneficial to alleviating this complication, as observed at 6 months (Table 4; $\mathrm{P}=0.038$ ).

Meal frequency following RYGB or gastric banding was documented by Wardé-Kamar et al. ${ }^{24}$ and Restuccia et al. ${ }^{25}$ Moreover, Wardé-Kamar et al. ${ }^{24}$ reported that after 30 months, energy intake was $1733 \pm 630 \mathrm{Kcal} /$ day. Patients fed themselves six times a day, a routine that was not criticized because the weight loss was quite adequate $(58 \pm 17 \%)$.

Restuccia et al. ${ }^{25}$ showed an association between weight loss and diet pattern, but only after 18 months following RYGB. Nevertheless, in non-operated children and adolescents, it is well established that a greater number of snacks and, particularly, a greater of meals in the absence of hunger result in increased body weight. ${ }^{26}$ After bariatric intervention, it was recently shown that snack-eating, and multiple meals in general, are deleterious for BMI normalization. $^{27}$

Total ingestion should not be overlooked, and the results reported here were globally low $(536 \pm 295.7 \mathrm{Kcal} /$ day by 3 months and $829.0 \pm 398.2 \mathrm{Kcal} / \mathrm{day}$ at 9 months). These data are consistent with the case-report of undernutrition by Kushner, ${ }^{28}$ but not with the conventional experience reported by Skroubis et al..$^{29}$ and Bobbioni et al. ${ }^{30}$ who noted more substantial values $(900-1000 \mathrm{Kcal} / \mathrm{day}$ and $1140 \pm 420$ Kcal/day during the 6 first months, respectively). Such a downward trend in food ingestion appears to be typical of public hospitals in Brazil and has already been reported by Dias et al. ${ }^{6}$

In the initial 3 months, more calories were consumed by our patients who ate six times per day than by those that had only three meals (Table 3 ). The impact on weight loss was not evident at this point, likely because the total daily volume at this stage was extremely low (slightly above 500 $\mathrm{Kcal} / \mathrm{day})$. Nonetheless, weight loss tended to correlate with dietary energy both at 3 and 9 months $(P=0.063$ and $P=$ 0.051, respectively; Table 4).

In light of the present observations, which are consistent with those of Leite-Faria et al. under similar conditions, ${ }^{27} \mathrm{a}$ standard regimen of three meals/day appears to be an option to be considered against insufficient weight loss.

More divided meals should only be planned in specific settings, such as those involving patients with limited food tolerance and frequent vomiting, those that are addicted to or unable to change an all-day-grazing routine due to social or psychological reasons or when it is believed that numerous 
scheduled meals will inhibit consumption of even more damaging calorie-dense snacks.

The impact of comorbidities on weight loss was not addressed in this protocol. In a recent article with a comparable population, it was noted that diabetics tended to lose less weight than non-diabetics, particularly in the first two years. ${ }^{31}$

Our study suffers from the weaknesses intrinsic in any observational protocol. There was no intervention concerning the frequency of meals or choleric consumption, and the distribution was not previously determined. The outcome depended on the spontaneous decisions of the patients or the eventual recommendations of their surgeon. As a consequence, the numbers were occasionally skewed, and statistical significance could only be achieved at certain points.
Physical exercise was also not evaluated in this study. Although patients were mostly sedentary housewives, in rare circumstances, vigorous exercising can introduce a bias in weight loss findings.

Additional investigations are needed to better elucidate the various factors interfering with diet, vomiting and weight loss in individuals with bariatric devices.

\section{CONCLUSIONS}

1) Frequent small meals were associated with reduced weight loss after gastric bypass and with decreased vomiting episodes at 6 months, and 2) vomiting did not interfere with nutritional outcome. Unless required due to vomiting or other reasons, multiple small meals may not be advantageous after bariatric intervention.

\section{REFERENCES}

1. Wang Y, Beydoun M A. The obesity epidemic in the United States-gender, age, socioeconomic, racial/ethnic, and geographic characteristics: a systematic review and meta-regression analysis. Epidemiol Rev. 2007;29:6-28.

2. O'Brien PE, McPhail T, Chaston TB. Systematic Review of MediumTerm Weight Loss after Bariatric Operations. Obes Surg. 2006;16:103240.

3. Furnes MW, Tommeras K, Skoglund T, Arum C-J, Zhao C-M, Chen D. Gastric bypass surgery causes body weight loss without reducing food intake in rats. Obes Surg. 2008;18:415-22.

4. Anderson WA, Geoffrey W, Greene R, Forse A, Caroline M, Apovian $\mathrm{V}$, et al. Weight Loss and health outcomes in African Americans and white after gastric bypass surgery. Obesity. 2007;15:1455-62.

5. Luis de DA, Sagrado MG, Izaola O, Terroba MC, Cuellar L, Conde $\mathrm{R}$, et al. Influence of ALA54Thr polymorphism of fatty acid-bonding protein-2 on clinical results of biliopancreatic diversion. Nutrition. 2008;24:300-4.

6. Dias MCG, Ribeiro AG, Scabim VM, Faintuch J, Zilberstein B, Rodrigues JG. Dietary intake of female bariatric patients after antiobesity gastroplasty. Clinics. 2006;61:93-8.

7. Scopinaro N. Biliopancreatic diversion: mechanisms of action and long-term results. Obes Surg. 2006;16:683-9.

8. Fabry P, Hejl Z, Fodor J, Braun T, Zvolankova K. The frequency of meals: its relation to overweight. hypercholesterolemia. and decreased glucose-tolerance. Lancet. 1964;18:614-15.

9. Edelstein SL, Barrett-Connor EL, Wingard DL, Cohn BA. Increased meal frequency associated with decreased cholesterol concentrations; Rancho Bernardo CA. 1984-1987. Am J Clin Nutr. 1992;55:664-9.

10. Kant AK, Schatzkin A, Graubard BI, Ballard-Barbash R. Frequency of eating occasions and weight change in the NHANES I Epidemiologic Follow-Up Study. Int J Obes Relat Metab Disord. 1995;19;468-74.
11. Franko DL, Striegel-Moore HR, Thompson D, Affeniot SG, Schreiber $\mathrm{Gb}$, Daniel SR, et al. The relationship between meal frequency and body mass index in black and white adolescent girls: more is less. Int J Obes. 2007;32:23-9.

12. Bellisle F, McDevitt R, Prentice AM. Meal frequency and energy balance. Br J Nutr. 1997;77 Suppl 1:S57-70.

13. Jenkins DJ, Khan A, Jenkins AL, Illingworth R, Pappu AS, Wolever TM, et al. Effect of nibbling versus gorging on cardiovascular risk factors: serum uric acid and blood lipids. Metabolism. 1995;44:549-55.

14. Jenkins DJ, Wolever TM, Vuksan V, Brighenti F, Cunnane SC, Rao AV, et al. Nibbling versus gorging: metabolic advantages of increased meal frequency. N Engl J Med. 1989;321:929-34.

15. Faintuch J, Marques PC, Bortolotto LA, Faintuch JJ, Cecconello I. Systemic inflammation and cardiovascular risk factors: are morbidly obese subjects different? Obes Surg. 2008 ;18:854-62.

16. Ocon B, Naranjo J, Laborda SP, Ruesca PB, Hernández RG. Eficacia y complicaciones de la cirugía bariátrica en el tratamiento de la obesidad mórbida. Nutr. Hosp. 2005;20:409-14.

17. Israel A., Sebba G, Fraser D, Lev Y. Nutritional behavior as a predictor of early success after vertical gastroplasty. Obes. Surg. 2005;15:88-94.

18. Crookes PF. Surgical treatment of morbid obesity. Ann Rev Med. 2006;57:243-64.

19. Decker GA, James M, Swain MD, Michael D, Crowell D, Scolapio JS. Gastrointestinal and nutritional complications after bariatric surgery. Am J Gastroenterol. 2007;102:2571-80.

20. Martin LF, Tan TL, Holmes PA, Becker DA, Horn J, Mann LD, et al Preoperative insurance status influences postoperative complication rates for gastric bypass. Am J Surg. 1991;161:625-43.

21. Naslund I, Jarnmark. I, Andersson. H. Dietary intake before and after gastric bypass and gastroplasty for morbid obesity in women. Int J Obes. 1988;12:503-13 
22. Faintuch J, Matsuda M, Cruz ME, Silva MM, Teivelis MP, Garrido AB $\mathrm{Jr}$, et al. Severe Protein-Calorie Malnutrition after bariatric procedures. Obes. Surg. 2004; 14:175-81

23. Chaves LC, Faintuch J, Kahwage S, Alencar Fde A. A cluster of polyneuropathy and Wenicke-Korsakoff syndrome in a bariatric unit. Obes Surg. 2002;12:328-34.

24. Wardé-Kamar J, Rogers M, Flancbaum L, Laferrère B. Caloric intake and meal patterns up to 4 years after Roux-en-Y gastric bypass surgery. Obes Surg. 2004; 14:1070-9.

25. Restuccia N, Olivero-Rivera L, Daud A, Digiorgi MF, Skuro-Urban M, Janice B, et al. Surg Obes Relat Dis. 2005;1:244-44.

26. Hill C, Llewellyn CH, Saxton J, Webber L, Semmler C, Carnell S, et al Adiposity and "eating in the absence of hunger" in children. Int J Obes (Lond). 2008;32:1499-505.
27. Leite Faria S, de Oliveira Kelly E, Pereira Faria O, Kiyomi Ito M. Snack-Eating Patients Experience Lesser Weight Loss after Roux-En-Y Gastric Bypass Surgery. Obes Surg. 2008 Oct 2. [Epub ahead of print].

28. Kushner. R. Managing the Obese Patient after Bariatric Surgery. A Case Report of Severe Malnutrition and Review of the Literature. JPEN. 2000;24:126-31.

29. Skroubis SG, Sakella G, Pouggouras K, Mead N, Nikiforidis G, Kalfarentzos F. Comparison of nutritional deficiencies after Roux-en-Y gastric bypass. Obes Surg. 2002;12:551-8.

30. Bobbioni-Harsch E, Huber O, Morel P, Chassot G, Lehmann T, Volery $\mathrm{M}$, et al. Factors influencing energy intake and body weight loss after gastric bypass. Eur J Clin Nutr. 2002;56:551-6.

31. Dalcanale L, Oliveira CPMS , Faintuch J, Nogueira MA, Rondó P, Lima VMR, et al. Long term nutritional outcome after gastric bypass. Obes Surg. 2009; In print. 